\title{
GLIFOSATOE E GLUFOSINATO COMO AGENTES SELETIVOS PARA TRANSFORMAÇÃO GENÉTICA DE MARACUJÁ AMARELO (Passiflora edulis f. flavicarpa Deg.)
}

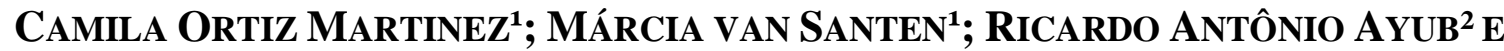 MARLUCE GONÇALVES CORTEZ ${ }^{3}$}

${ }^{1}$ Graduada em Engenharia Agronômica. UEPG/Depto Fitotecnia e Fitossanidade. Av. Carlos Cavalcanti, 4748, Bloco F Cep 84030 - 900. Ponta Grossa, PR. camila_ortizmartinez@yahoo.com.br. Telefone: (19)32131710.

2 Professor Dr. UEPG/Depto Fitotecnia e Fitossanidade. rayub@uepg.br. (42)2203088

${ }^{3}$ Professora Dr ${ }^{\mathrm{a}}$. UEPG/Depto Fitotecnia e Fitossanidade. mgcortez@uepg.br. (42)2203094

\section{RESUMO}

\section{GLIFOSATO E GLUFOSINATO COMO AGENTES SELETIVOS PARA TRANSFORMAÇÃO GENÉTICA DE MARACUJÁ AMARELO (Passiflora edulis f. flavicarpa Deg.)}

O maracujá amarelo é uma das espécies de maior interesse econômico da família Passifloraceae. A biotecnologia pode contribuir para solucionar alguns dos principais problemas que afetam o seu potencial produtivo, como murcha precoce e a suscetibilidade à bacteriose, assim como a criação de variedades mais produtivas. Neste contexto foi conduzido um experimento com o objetivo de avaliar os herbicidas glifosato e glufosinato como agentes seletivos para transformação genética de maracujá amarelo. Foi utilizado o meio de cultura Murashige \& Skoog (1962) suplementado com as vitaminas B5, 30 g.L.-1 de sacarose, 100 mg. $\mathrm{L}^{-1}$ de inositol, $1 \mathrm{mg} . \mathrm{L}^{-1}$ de BAP e solidificado com 2,6 g. $\mathrm{L}^{-1}$ de Phytagel $\circledast$. O delineamento experimental foi inteiramente casualizado e avaliados os experimentos de neoformação de gemas e rizogênese. Os tratamentos com glifosato para a neoformação de gemas corresponderam às concentrações $0 ; 0,2 ; 0,4 ; 0,6 ; 0,8 ; 1,0 \mathrm{mg} . \mathrm{L}^{-1}$, que, para rizogênese foram $0 ; 0,05 ; 0,1 ; 0,15 ; 0,20 ; 0,30 ; 0,40 \mathrm{mg} \cdot \mathrm{L}^{-1}$. No caso do glufosinato para a formação de gemas utilizou-se as concentrações 0,$0 ; 0,2 ; 0,4 ; 0,6 ; 0,8 \mathrm{mg} \cdot \mathrm{L}^{-1}$, e para a rizogênese 0,$0 ; 0,1 ; 0,15$; 
0,20; 0,25 mg.L $\mathrm{L}^{-1}$. A neoformação de gemas foi avaliada pelo número de explantes com gemas e o número médio de gemas por explante, e a rizogênese pelo número de ápices meristemáticos enraizados, o comprimento da maior raiz, o número de raízes primárias e a biomassa de raízes. Ambos os herbicidas glifosato e glufosinato foram eficientes na inibição da regeneração de brotos a uma baixa concentração $\left(0,785 \mathrm{mg} . \mathrm{L}^{-1}\right.$ e $0,768 \mathrm{mg} . \mathrm{L}^{-1}$ respectivamente). Assim como na inibição do enraizamento $\left(0,404 \mathrm{mg} \cdot \mathrm{L}^{-1}\right.$ e $0,249 \mathrm{mg} \cdot \mathrm{L}^{-1}$ respectivamente). Isso permite a recomendação desses herbicidas como agentes seletivos na cultura de tecidos do maracujá para trabalhos de transferência gênica.

Palavras-chave: agentes seletivos, maracujá, neoformação de gemas, rizogênese, transformação genética. 


\section{ABSTRACT \\ GLYPHOSATE AND GLUFOSINATE AS SELECTIVE AGENTS FOR GENETIC TRANSFORMATION OF YELLOW PASSION FRUIT (Passiflora edulis f. flavicarpa Deg.)}

The yellow passion fruit is one of the most interesting economic species of Passifloraceae family. The biotechnology tools are useful to solve some problems that affect the productive potencial of this specie, like fungal and bacterial diseases, and the creation of more productivity varieties. In this context an experiment of yellow passion fruit was corried out to evaluate the glyphosate and gluphosinato herbicides as selective agents for genetic transformation. The culture medium used was Murashige \& Skoog (1962) supplemented with B5 vitamin and organic complex, 30 g.L $\mathrm{L}^{-1}$ sucrose, $100 \mathrm{mg} . \mathrm{L}^{-1}$ inositol, $1 \mathrm{mg} . \mathrm{L}^{-1}$ 6benzilaminopurina, solidified with 2,6 g. $\mathrm{L}^{-1}$ Phytagel ${ }^{\circledR}$. The experimental design was entire occasional and the bud regeneration and rooting formation experiments were evaluated. The glyphosate concentrations used in experiments of bud regeneration were: $0 ; 0,2 ; 0,4 ; 0,6 ; 0,8$; $1,0 \mathrm{mg} \cdot \mathrm{L}^{-1}$, for rooting experiments: $0 ; 0,05 ; 0,1 ; 0,15 ; 0,20 ; 0,30 ; 0,40 \mathrm{mg} \cdot \mathrm{L}^{-1}$. The glufosinate treatments for bud regeneration were: 0,$0 ; 0,2 ; 0,4 ; 0,6 ; 0,8 \mathrm{mg} . \mathrm{L}^{-1}$ and for rooting experiments: 0,$0 ; 0,1 ; 0,15 ; 0,20 ; 0,25 \mathrm{mg} \cdot \mathrm{L}^{-1}$. Number of explant with shoots and number of shoots per explant were evaluated in the experiment of caulogenesis. For rooting evaluation: number of rooted apexes, root size, primary root number and root fresh weight. Both herbicides glyphosate and glufosinate were efficient in the inhibition of the bud regeneration to a low concentration $\left(0,785 \mathrm{mg} . \mathrm{L}^{-1}\right.$ e $0,768 \mathrm{mg} . \mathrm{L}^{-1}$ respectively), as well as in the inhibition of rooting (0,404 mg.L $\mathrm{L}^{-1}$ e $0,249 \mathrm{mg} . \mathrm{L}^{-1}$ respectively). That allows the recommendation of those herbicides as selective agents in tissue culture of passion fruit for works of genetic transfer.

Key words: selective agents, passion fruit, bud regeneration, rhizogenesis, genetic transfer. 


\section{INTRODUÇÃO}

A família Passifloraceae consiste de 12 gêneros, sendo Passiflora o mais cultivado. Este gênero está representado por 465 espécies das quais a maioria é encontrada nas regiões tropicais da América do Sul (Vanderplank, 1996). O maracujá amarelo (Passiflora edulis f. flavicarpa Deg.) é uma das espécies mais importantes do ponto de vista econômico, por sua excelente aceitação no mercado. É cultivado principalmente por seus frutos comestíveis, ricos em vitamina $\mathrm{C}$ e ácido nicotínico, e em menor escala para fins ornamentais e farmacêuticos.

O Brasil possui uma posição de destaque quanto à cultura do maracujazeiro, pois é o maior produtor mundial de maracujá (FNP Consultoria \& Comércio, 2002). Contudo, de forma geral, a produtividade ainda é baixa. A cultura apresenta problemas crescentes em relação à propagação, fitossanidade (bacteriose, murcha precoce, dentre outros) e falta de variedades mais produtivas. Essas limitações comprometem a produção, qualidade dos frutos e rendimento da cultura. Hoje o melhoramento vegetal através da biotecnologia é uma realidade, sendo provavelmente a técnica mais indicada para produção de plantas tolerantes a esses problemas (Lima et al., 2000).

A descrição e otimização de protocolos de cultura de tecidos são importantes para a definição de estratégias para amplificar a multiplicação e transformação genética. $\mathrm{O}$ processo de cultura de tecidos do maracujá apresenta uma metodologia definida (Lima et al., 2000). O tecido juvenil, além de ser apropriado para isolamento de protoplastos (Dornelas \& Vieira, 1993; d'Utra Vaz et al., 1993), é também adequado à micropropagação e à obtenção de brotos adventícios (Dornelas \& Vieira, 1994; Kawata et al., 1995).

Assim como a obtenção de um sistema eficiente de regeneração de plantas, o desenvolvimento de um método seguro para a seleção de plantas transformadas, a uma freqüência suficientemente alta, constitui um importante fator para obtenção de uma transformação gênica eficiente. $O$ conhecimento sobre a tolerância relativa dos tecidos vegetais a agentes seletivos, como os antibióticos e os herbicidas, para os quais existem marcadores de resistência, facilitam a transferência gênica (Humara \& Ordás, 1999).

$\mathrm{Na}$ transformação, o gene de seleção que usualmente determina uma resistência a antibiótico ou a herbicida, é introduzido conjuntamente com o gene de interesse, de modo a 
favorecer a seleção de poucas células transgênicas numa grande população de células normais (Nap et al., 1992). O gene Aro A, isolado da bactéria Salmonela typhimurium (Ochman \& Wilson, 1987), confere à planta resistência ao glifosato (Bellinder et al, 1985), enquanto a resistência à canamicina, geneticina, neomicina e paromomicina é obtida pela expressão do gene aphA2 de Tn5 de Escherichia coli (Bevan et al., 1983).

A canamicina é amplamente utilizada como agente seletivo, mas certas espécies de plantas são bastante resistentes, como tabaco e cenoura, e outras são extremamente sensíveis, como o pinus, sendo para este indicado o uso de glufosinato (Humara \& Ordás, 1999). Este também foi indicado como agente seletivo eficiente na inibição de calos de café a $3 \mathrm{mg}^{-L^{-1}}$ (Van Boxtel et al., 1997), e tem sido bem sucedido em muitas plantas como Brassica napus, Helianthus annus, Zea mays, Avena sativa, Orysa sativa (Wilmink \& Dons, 1993).

O herbicida conhecido como glufosinato, chamado fosfinotricina (PPT), atua como inibidor competitivo da enzima glutamina sintetase (GS), a qual está envolvida na assimilação de amônia e possui uma função chave na regulação do metabolismo de nitrogênio (De Block et al., 1987). A PPT é sintetizada quimicamente ou por fermentação de Streptomyces hygroscopicus (Thompson et al., 1987), neste caso, sendo chamada de Bialaphos $®$.

A resistência a PPT é conferida pela enzima fosfinotricina-N-acetiltransferase (PAT), que o inativa por acetilação do grupo $\mathrm{NH}_{2}$ livre, usando acetil coenzima A como cofator. Os genes que codificam para PAT são o gene bar, isolado de Streptomyces hygroscopicus (Thompson et al., 1987), e o gene pat isolado de S. viridochromogenes (Wohlleben et al., 1988). Esse último foi clonado e introduzido em fumo e cenoura com sucesso (Strauch et al., 1988; Droge et al., 1992).

O glifosato também pode ser testado como possível agente seletivo. Existem evidências de que o glifosato tem um único sítio de ação primário, a rota do shiquimato, onde circula pelo menos $20 \%$ do carbono fixado pela fotossíntese nas plantas. Esta é a fonte biossintética de três aminoácidos aromáticos essenciais: fenilanina, triptofano e tirosina, os quais são necessários para síntese de proteína, biossíntese de auxinas e da maioria dos componentes fenólicos da planta e outros componentes secundários (Devine et al., 1993; Almeida \& Ulbrich, 1999). 
O glifosato bloqueia a condensação de fosfoenolpiruvato (PEP) e shiquimato-3-fosfato (S3P) que dá origem a 5-enolpiruvilshiquimato-3-fosfato (EPSP) e fosfato inorgânico. Esta reação é catalisada pela enzima 5-enolpiruvilshiquimato-3-fosfato sintase (EPSPS). O herbicida liga-se a região da EPSPS que tem que se unir ao fosfato do PEP. O bloqueio da síntese de shiquimato conduz à desregulação da rota metabólica, o que resulta em acumulação de shiquimato e de derivados dos ácidos benzóicos de shiquimato. Isto pode conduzir a uma série de efeitos fisiológicos potencialmente fitotóxicos (Devine et al., 1993; Almeida \& Ulbrich, 1999).

Este trabalho teve como objetivo avaliar os herbicidas glifosato e glufosinato como agentes seletivos para transformação genética, na cultura de tecidos de maracujá amarelo.

\section{MATERIAL E MÉTODOS}

O trabalho foi conduzido no Laboratório de Biotecnologia Vegetal da Universidade Estadual de Ponta Grossa, PR, Brasil. O material vegetal foi obtido a partir de sementes de maracujá amarelo, germinadas aos 30 dias após semeadura em substrato contendo terra e vermiculita, sendo constituído de folhas cotiledonares e ápices meristemáticos. Sendo o primeiro destinado ao experimento de organogênese, e o segundo para o experimento de rizogênese.

Procedeu-se a desinfestação do material vegetal através de sua imersão em etanol $70 \%$ (v/v) durante 40 segundos, e na seqüência em hipoclorito de sódio $2 \%$ (v/v), contendo $1 \%$ de Tween 80, por 15 minutos. Em seguida, o material foi submetido a quatro banhos em água esterilizada com duração de 5 minutos cada um (Dornelas \& Vieira, 1994).

Cada folha cotiledonar foi dividida em seis explantes $(0,3 \mathrm{~cm})$ por placa de Petri, sendo cada tratamento constituído de cinco placas, totalizando 30 explantes, os quais foram colocados com a face adaxial em contato com o meio de cultura. Após a inoculação, as placas foram seladas com filme plástico de polietileno. Os ápices meristemáticos foram apenas encurtados após a esterilização.

O meio de cultura utilizado para a neoformação de gemas foi o MS (Murashige \& Skoog, 1962), suplementado com vitaminas B5 e componentes orgânicos (Gamborg et al., 
1968), 30 g. $\mathrm{L}^{-1}$ de sacarose, $100 \mathrm{mg} . \mathrm{L}^{-1}$ de inositol, $1 \mathrm{mg} . \mathrm{L}^{-1}$ de 6 -benzilaminopurina (BAP) e solidificado com 2,6 mg.L $\mathrm{L}^{-1}$ de Phytagel® (Sigma Chemical Company, USA). No ensaio de rizogênese foi utilizado o mesmo meio de cultura com a concentração dos sais diluída até a metade, e sem fitorreguladores. Os meios de cultura foram preparados por dissolução dos componentes em água destilada. $\mathrm{O} \mathrm{pH}$ foi ajustado para $5,8 \mathrm{com} \mathrm{NaOH} 0,1 \mathrm{~N}$ antes da adição do Phytagel $®$. Em seguida, os meios foram autoclavados por 20 minutos à $120^{\circ} \mathrm{C}$. Posteriormente foi adicionado o glifosato (Roundup ${ }^{\circledR}$ ) nas concentrações de 0,$0 ; 0,2 ; 0,4 ; 0,6$; 0,8; 1,0 mg. $\mathrm{L}^{-1}$ ao meio destinado a neoformação de gemas, distribuindo-se $20 \mathrm{ml}$ por placa de Petri. Ao meio destinado à rizogênese foi adicionado glifosato nas concentrações de 0,0;0,05; 0,$1 ; 0,15 ; 0,20 ; 0,30 ; 0,40 \mathrm{mg} \cdot \mathrm{L}^{-1}$. As concentrações de glufosinato (Finale ${ }^{\circledR}$ ), utilizadas sob as condições citadas anteriormente, para neoformação de gemas foram 0,$0 ; 0,2 ; 0,4 ; 0,6 ; 0,8$ mg. $\mathrm{L}^{-1}$, e para rizogênese: 0,$0 ; 0,1 ; 0,15 ; 0,20 ; 0,25$ mg. $\mathrm{L}^{-1}$.

O material foi mantido em câmara de cultivo em condições controladas de temperatura $\left(25 \pm 2^{\circ} \mathrm{C}\right)$ e de irradiância $\left(9 \mu \mathrm{mol} \cdot \mathrm{m}^{2} \cdot \mathrm{s}^{-1}\right)$, com fotoperíodo de $16 \mathrm{~h}$. O material destinado à avaliação da regeneração de gemas permaneceu uma semana no escuro, sendo posteriormente transferido para luz, onde foi mantido durante 53 dias. O material utilizado para obtenção da rizogênese permaneceu na luz durante 45 dias.

O delineamento foi inteiramente casualizado, com seis tratamentos e cinco repetições para neoformação de gemas; e sete tratamentos com oito repetições para rizogênese com relação ao glifosato. Quanto aos ensaios com glufosinato utilizou-se o mesmo número de repetições empregado para o glifosato, porém o número de tratamentos foi igual a cinco para ambos os experimentos. Um número maior de repetições foi utilizado nos ensaios de rizogênese (glifosato) em função das contaminações microbiológicas elevadas. A diferença de concentrações de herbicidas nos experimentos (rizogênese e neoformação de gemas) foi adotada considerando o fato da rizogênese ser geralmente um processo mais sensível.

Para o ensaio de regeneração de gemas avaliou-se o número médio de explantes com gemas adventícias e o número médio de gemas por explante. Para o ensaio de rizogênese foram avaliados o número de ápices enraizados, a biomassa de raizes, o comprimento da maior raiz e o número de raízes primárias. 
Os dados foram submetidos à análise de variância (ANOVA) e as médias comparadas pele teste de Tukey a 5\% de probabilidade, utilizando-se o programa Estat da UNESP de Jaboticabal, SP. As doses responsáveis pela inibição de 100\% da organogênese e rizogênese foram estimadas através de curvas dose-resposta, obtidas de modelos matemáticos propostos e ajustados pelo programa Curve Expert 1.3., um sistema próprio para Windows, onde os dados podem ser modelados através de modelos como regressão linear e não linear e interpolação.

\section{RESULTADOS E DISCUSSÃO}

As variáveis medidas nos experimentos (neoformação de gemas e rizogênese) apresentaram diferenças significativas na resposta à aplicação das doses de ambos os herbicidas, comprovadas ao nível de 5\% de probabilidade pelo teste de Tukey (FIGURAS 1, 2 e 3).

Observou-se para a organogênese uma tendência de resposta não linear de inibição, com o aumento da concentração do herbicida, sendo o modelo matemático 'Rational function' o que melhor se ajustou aos resultados obtidos com a utilização de glifosato (FIGURA 1A e B), e o quadrático com a aplicação de glufosinato (FIGURA 1C e D).

Os resultados indicaram que estes herbicidas são altamente seletivos em baixas concentrações para células de maracujá. A concentração de $0,785 \mathrm{mg} . \mathrm{L}^{-1}$ de glifosato provocou inibição completa da formação de explantes com gemas (FIGURA 1A), assim como 0,768 mg.L $\mathrm{L}^{-1}$ de glufosinato (FIGURA 1C). Van Boxtel et al. (1997) encontraram concentração superior à primeira (60 mg. $\mathrm{L}^{-1}$ de glifosato) para a inibição da proliferação de calos em tecido de café, variedade $C$. canephora clone 597, advindos de suspenção embriogênica, sendo ainda, que o tecido de café retoma o desenvolvimento de calos na ausência do herbicida, mostrando a necessidade de maiores concentrações deste para uma inibição completa. Quanto ao glufosinato, a concentração estimada é inferior à encontrada por Humara \& Ordás (1999) em cotilédones de Pinus pinea $\left(1 \mathrm{mg} . \mathrm{L}^{-1}\right)$, e bem mais baixa que a determinada por EnríquezObregón et al. (1997) para a cana de açúcar (4 mg.L $\left.\mathrm{L}^{-1}\right)$. 
A)

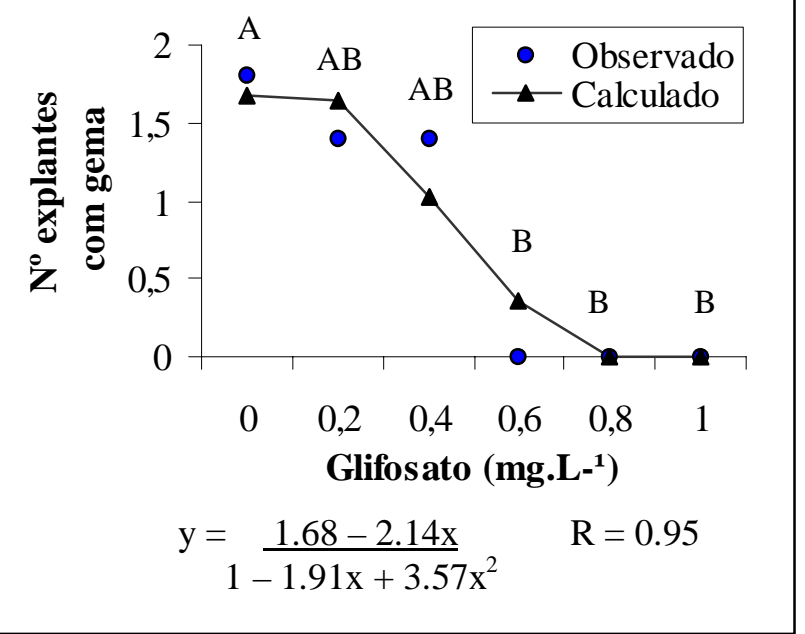

C)

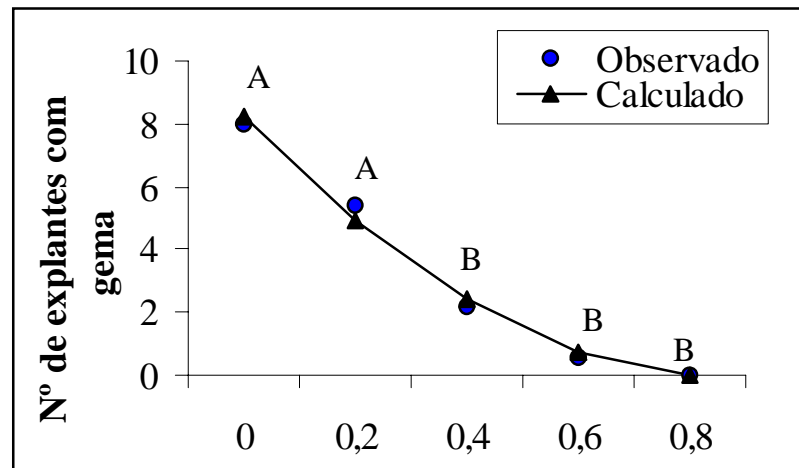

Glufosinato (mg.L-1)

$$
y=8.2-18.4 x+10 x^{2} \quad R=0.99
$$

B)

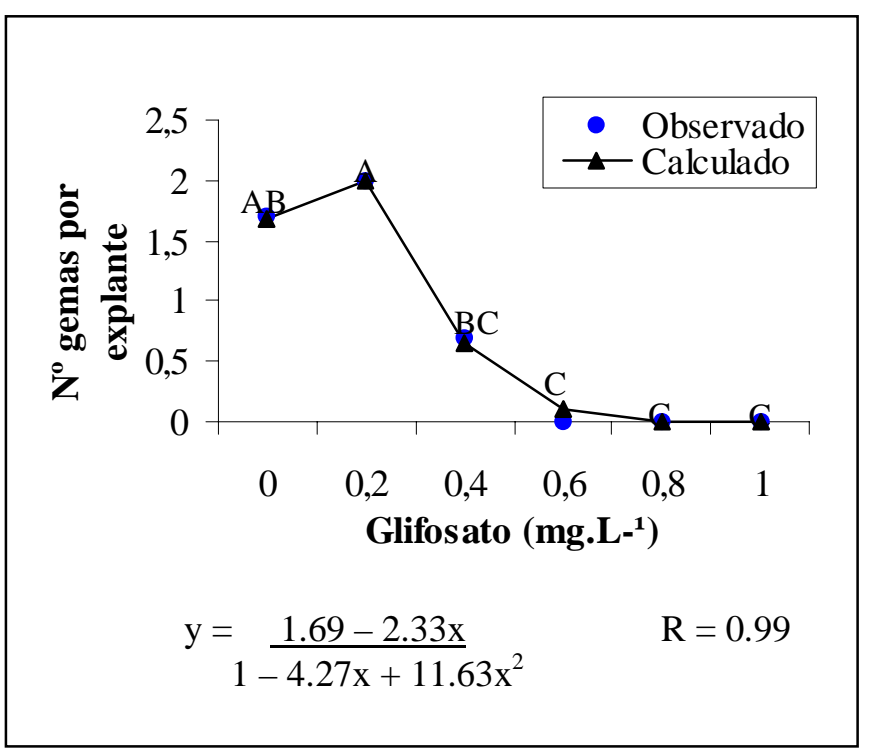

D)

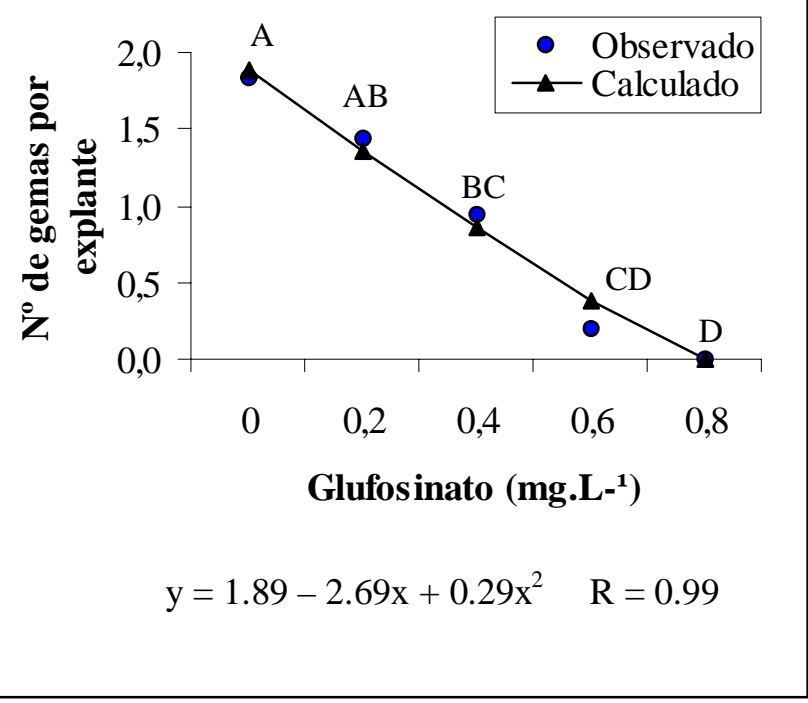

FIGURA 1. Sensibilidade do maracujazeiro amarelo na fase organogênica ao herbicida glifosato (A e B), e ao herbicida glufosinato (C e D). A e C: número médio de explantes com gema; B e D: número médio de gemas por explante, em função da concentração dos respectivos herbicidas $\left(\mathrm{mg} \cdot \mathrm{L}^{-1}\right)$. As letras sobre a média das variáveis se referem ao resultado do teste de Tukey (5\%). 
$\mathrm{Na}$ rizogênese, mediante aplicação de glifosato, o número de ápices enraizados e o número de raízes primárias apresentaram uma tendência de resposta quadrática com o aumento da concentração do herbicida (FIGURA 2 A e B). Já as variáveis comprimento da maior raiz e biomassa de raízes foram melhor ajustadas pelo modelo matemático polinomial de $3^{\circ}$ grau (FIGURA $2 \mathrm{C}$ e D), assim como todas as variáveis do experimento de rizogênese com a aplicação de glufosinato (FIGURA 3). A total inibição do enraizamento dos ápices foi estimada na concentração de $0,404 \mathrm{mg} . \mathrm{L}^{-1}$ de glifosato, e $0,249 \mathrm{mg} . \mathrm{L}^{-1}$ de glufosinato. Sendo esta última também encontrada para o comprimento da maior raiz quando se utilizou glufosinato.

Em concentrações inferiores a estas encontradas, tanto o desenvolvimento das gemas quanto o enraizamento ocorreram normalmente.

Estes resultados podem ser usados no desenvolvimento de plantas de maracujá geneticamente resistentes ao herbicida, que já demonstraram ser estáveis na sua descendência no caso do tabaco (Jones et al., 1996). Segundo Burnside (1992), estas plantas podem estimular o uso de herbicidas em culturas menos expressivas, como é o caso do maracujá, que são ignoradas atualmente pelo custo do desenvolvimento do herbicida e seu limitado potencial comercial.

Outras estratégias de uso a serem consideradas são a seleção in vitro de células resistentes ao herbicida, como o observado por Escorial et al. (1996) na cevada, nos ensaios para obtenção de resistência cruzada em beterraba açucareira (Hart et al., 1992), ou ainda a introdução do gene que determina produção de EPSPS (enzima 5-enolpiruvilshiquimato-3fosfato sintase) insensível a este herbicida em diversas culturas, incluindo soja e canola, obtendo indivíduos altamente resistentes (Almeida \& Ulbrich, 1999).

As condições hoje estabelecidas para o cultivo in vitro e a transformação gênica do maracujazeiro podem contribuir para a obtenção de novos cultivares com genes de interesse agronômico, beneficiando assim a expansão da cultura no país (Lima et al., 2000). 
A)

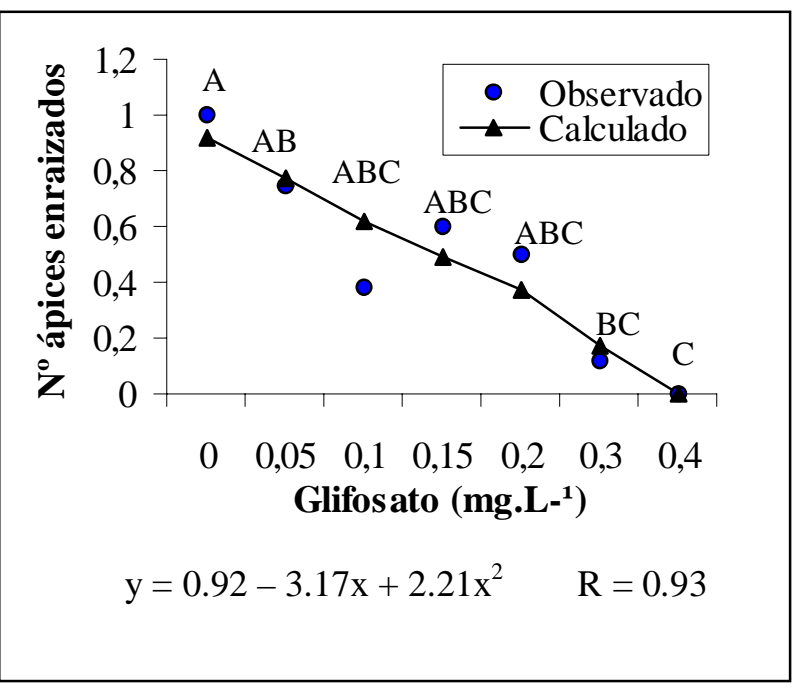

C)

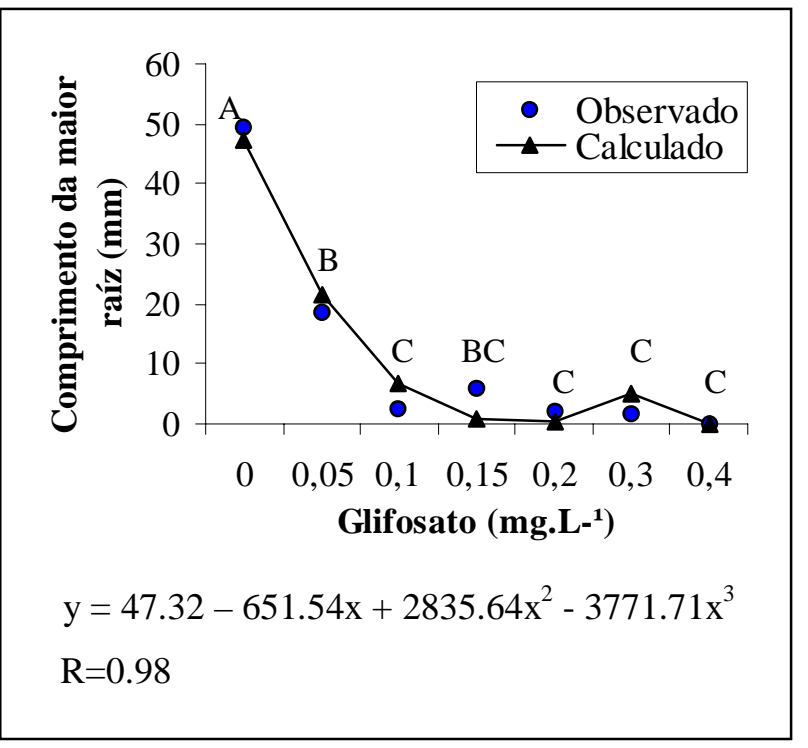

B)

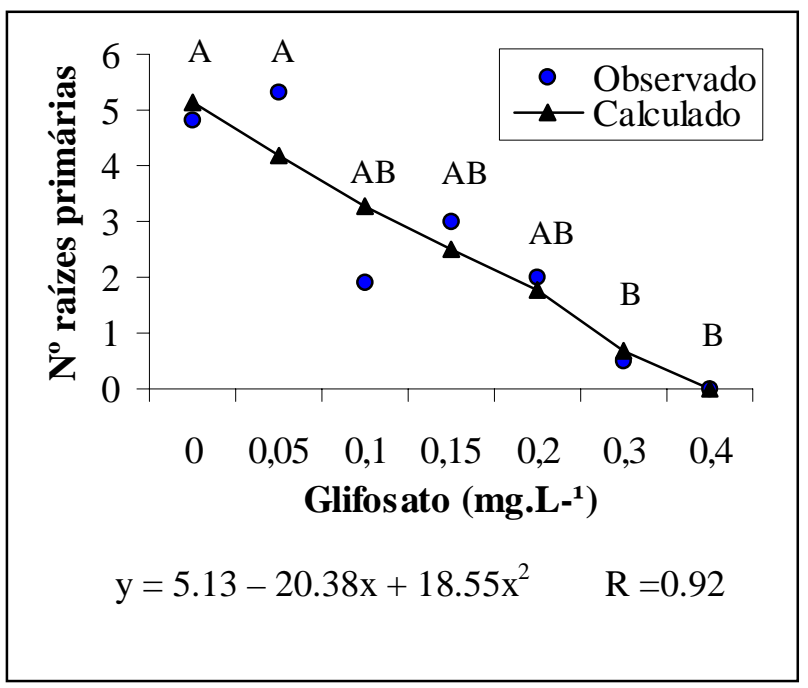

D)

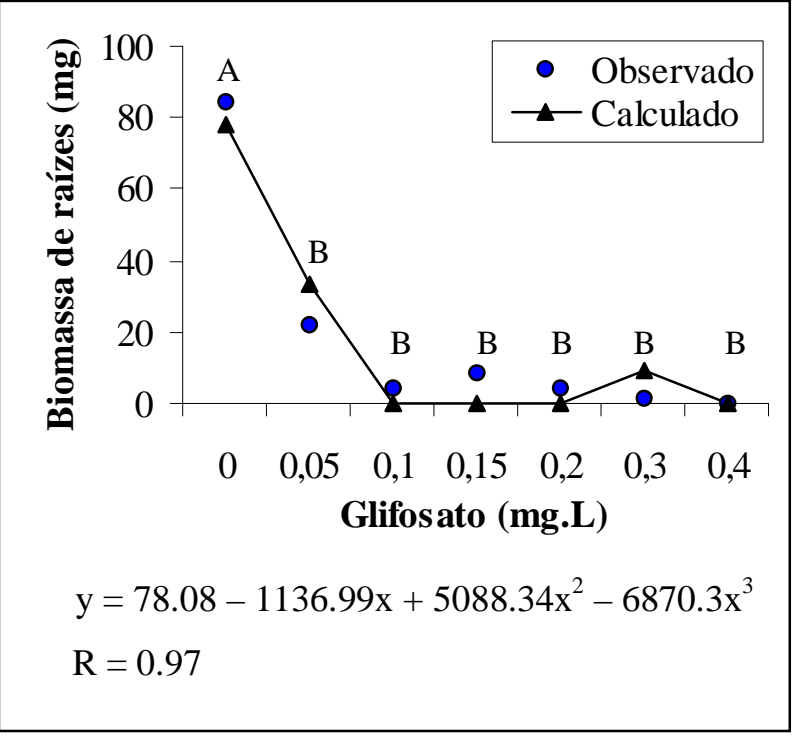

FIGURA 2. Sensibilidade do maracujazeiro amarelo na fase rizogênica ao herbicida glifosato. A) Número de ápices enraizados; B) Número de raízes primárias; C) Comprimento da maior raiz (mm) e D) Biomassa de raízes (mg), em função da concentração de glifosato (mg.L $\left.\mathrm{L}^{-1}\right)$. As letras sobre a média das variáveis se referem ao resultado do teste de Tukey $(5 \%)$. 
A)
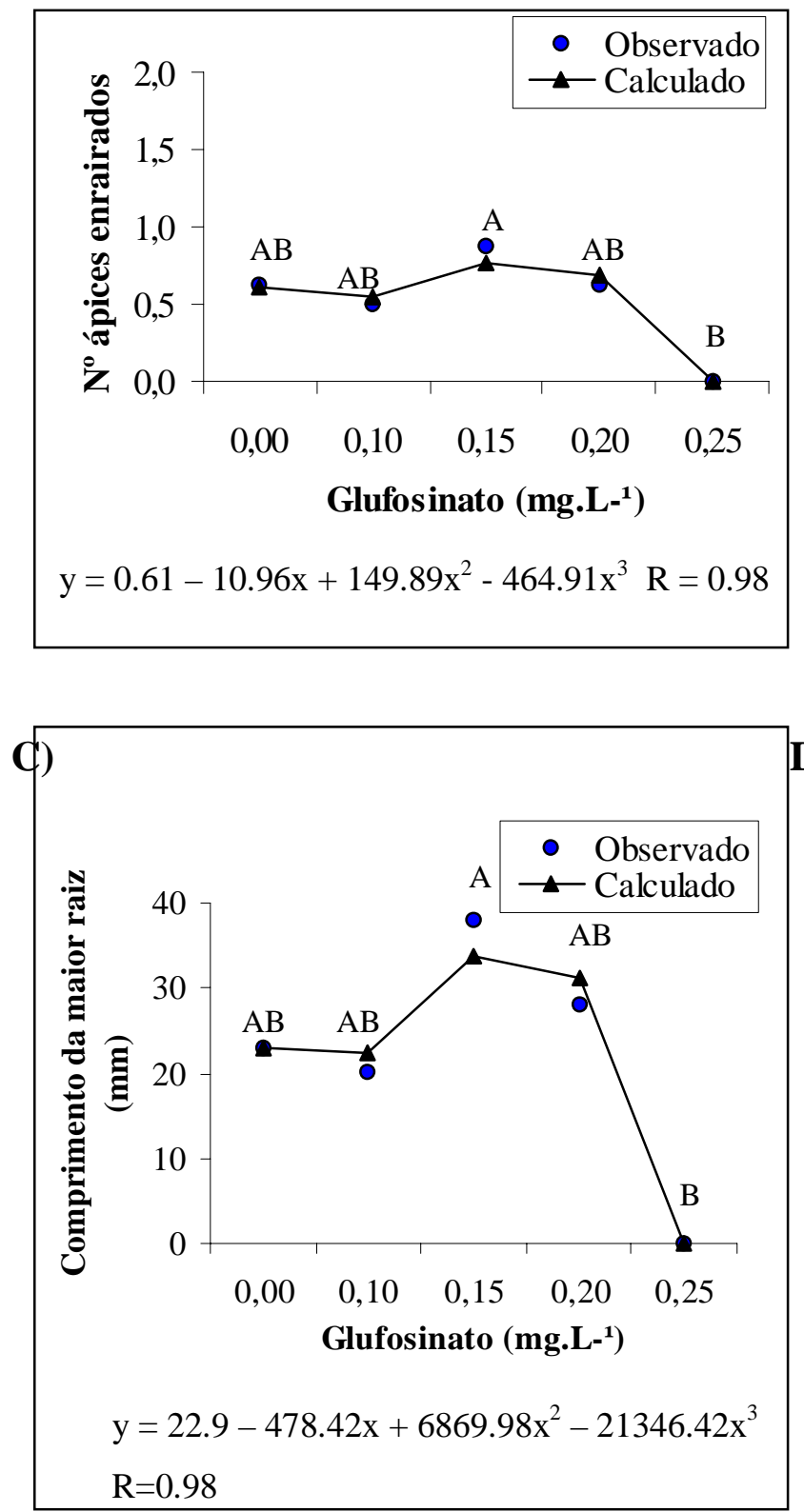

B)

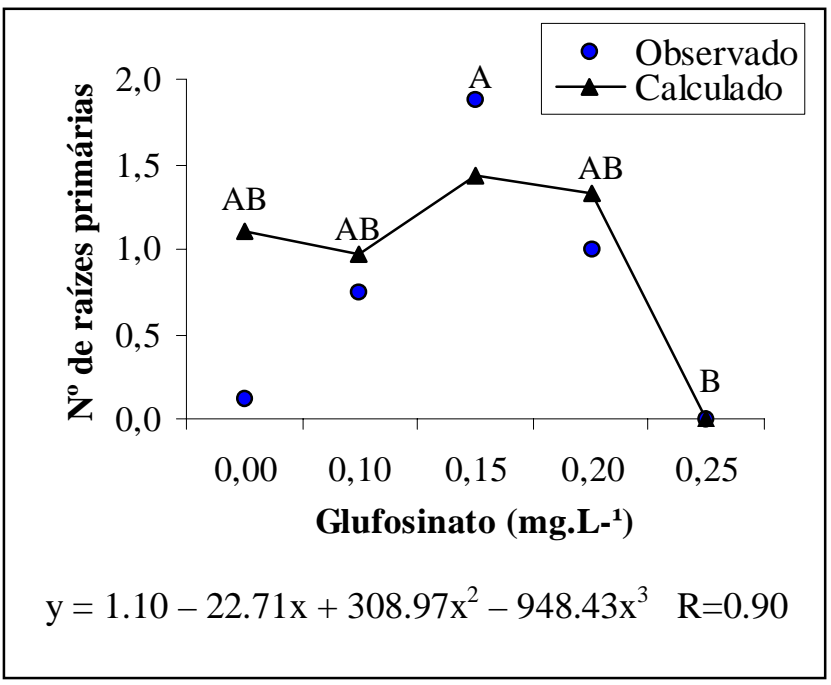

)

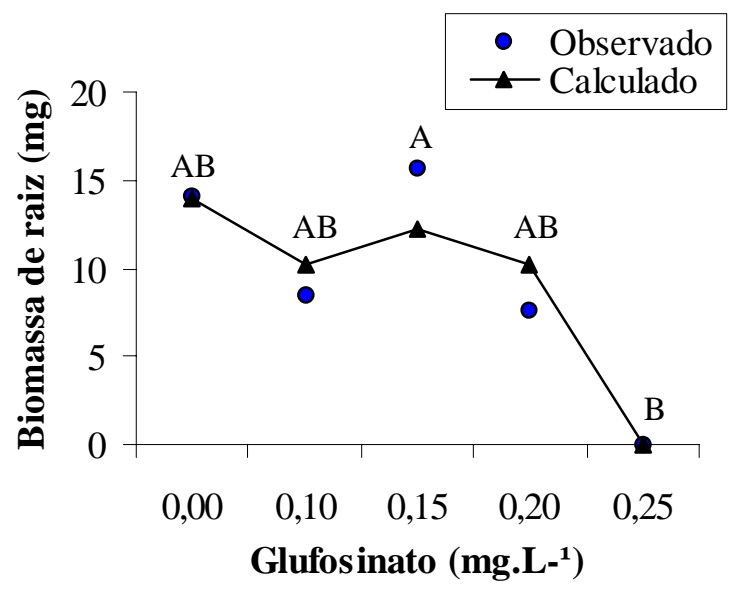

$$
\begin{aligned}
& y=13.95-186.65 x+2146.85 x^{2}-6537.61 x^{3} \\
& R=0.93
\end{aligned}
$$

FIGURA 3. Sensibilidade do maracujazeiro amarelo na fase rizogênica ao herbicida glufosinato. A) Número de ápices enraizados; B) Número de raízes primarias; C) Comprimento da maior raiz (mm) e D) Biomassa de raízes ( $\mathrm{mg}$ ), em função da concentração de glufosinato (mg. $\left.\mathrm{L}^{-1}\right)$. As letras sobre a média das variáveis se referem ao resultado do teste de Tukey $(5 \%)$. 


\section{CONCLUSÃO}

A análise dos resultados mostrou que as concentrações de $0,785 \mathrm{mg} . \mathrm{L}^{-1}$ de glifosato e 0,768mg. $\mathrm{L}^{-1}$ de glufosinato inibiram a formação de brotos, e que as concentrações de 0,404 mg. $\mathrm{L}^{-1}$ e $0,249 \mathrm{mg} . \mathrm{L}^{-1}$ respectivamente inibiram o enraizamento. Essas concentrações servem de base para seleção de plantas resistentes, em futuros trabalhos de transferência gênica no maracujá amarelo. 


\section{REFERÊNCIAS BIBLIOGRÁFICAS}

ALMEIDA, J. C. V. de; ULBRICH, A. V. Resistência aos herbicidas. In: MONTAlVÁN, R. \& DESTRO, D. (Ed.). Melhoramento genético de plantas. Londrina: UEL, 1999, cap. 36, p.713-730.

BELLINDER, R. R.; HATZIOS, K.K.; WILSON, H.P. Mode of action investigations with the herbicides HOE- 39866 and SC-0224 ${ }^{1}$. Weed Science, v.33, p.779-785, 1985.

BEVAN, M.; FLAVELL, R.; CHILTON, M. D. A chimaeric antibiotic resistance marker gene as a selectable marker for plant cell transformation. Nature, v.304, p.184-187, 1983.

BURNSIDE, O. C. Rationale for developing herbicide-resistant crops. Weed Technology, v.6, p.621-625, 1992.

DE BLOCK, M.; BOTTERMAN, J.; VANDEWIELE, M.; DOCKX, J.; THOEN, C.; GOSSELÉ,V.; RAO MOVVA, N.; THOMPSON, C.; VAN MONTAGU, M.; LEEMANS, J. Engineering herbicide resistance in plants by expression of a detoxifying enzyme. Embo Journal, v.6, p.2513-2518, 1987.

DEVINE, M.D.; DUKE S. O.; FEDTKE C. Physiology of herbicide action. New Jersey: PTR Prentice Hall, Englewood Cliffs, 1993. 439p. 
DORNELAS, M. C.; VIEIRA, M.L.C. Plant regeneration from protoplast cultures of Passiflora edulis var. flavicarpa Deg., P. amethystina Mikan and P. cincinata Mast. Plant Cell Reports, v.13, p103-106, 1993.

DORNELAS, M. C.; VIEIRA, M.L.C. Tissue culture studies on species of Passiflora. Plant Cell, Tissue and Organ Culture, v.36, p.211-217, 1994.

DROGE, W.; BROER, I.; PUHLER, A. Transgenic plants containing the phosphinothricin- $N$-acetyltransferase gene metabolize the herbicide Lphosphinothricin (glufosinate) differently from untransformed plants. Planta, v.187, p.142-151, 1992.

D’UTRA VAZ, F. B., SANTOS, A. V. P. dos, MANDERS, G.; COCKING, E. C.; DAVEY, M. R.; POWER, J. B. Plant regeneration from leaf mesophyll protoplasts of the tropical woody plant, passionfruit (Passiflora edulis fv. flavicarpa Degener): the importance of the antibiotic cefotaxime in the culture medium. Plant Cell Reports, v. 12, p.220-225, 1993.

ENRÍQUEZ-OBREGON, G.A; VÁSQUEZ-PADRÓN, R.I.; PIETRO-SAMSÓNOV, D.L.; PÉREZ, M.; SELMAN-HOUSEIN, G. Genetic transformation of sugarcane by A. tumefaciens using antioxidant compounds. Biotecnología Aplicada, v.14, p.169174, 1997.

ESCORIAL, M.C.; SIXTO, H.; GARCÍA-BAUDIN, J. M.; CHUECA, M.C. In vitro culture selection increases glyphosate tolerance in barley. Plant Cell, Tissue and Organ Culture, v.46, p.179-186, 1996.

FNP. Consulta \& Comércio. Agrianual 2002: anuário estatístico da agricultura brasileira. São Paulo 2002. 536p. 
GAMBORG, O. L; MILLER, R. A.; OJIMA, K. Nutrient requirement of suspension cultures os soybean root cells. Experimental Cell Research, v.50, p.151-158, 1968.

HART, S.E.; SAUNDERS, J.W.; PENNER, D. Chlorsulfuron-resistant sugarbeet: crossresistance and physiological basis of resistance. Weed Science, v.40, p.378-383, 1992.

HUMARA, J.M.; ORDÁS, R. J. The toxicity of antibiotics and herbicides on in vitro adventitious shoot formation on Pinus pinea L. cotyledons. In Vitro Cellular Developmental Biology Plant, v.35, p.339-343, 1999.

JONES, J.D.; GOLDSBROUGH, P.B.; WELLER, S.C. Stability and expression of amplified EPSPS genes in glyphosate resistant tobacco cells and plantlets. Plant Cell Reports, v.15, p.431-436, 1996.

KAWATA, K.; USHIDA, C.; KAWAI, F.; KANAMORI, M.; KURIYAMA, A. Micropropagation of passionfruit from subcultured multiple shoot primordia. Journal of Plant Physiology, v. 147, p.281-284, 1995.

LIMA, D. M. de; GOLOMBIESKY, E. R.; AYUB, R. A. Aplicação de técnicas de biotecnologia à cultura e melhoramento do maracujazeiro. Ciência Rural, v.30, n.2, p.359-363, 2000.

MURASHIGE, T.; SKOOG, F. A revised medium for rapid growth and bioassays with tobacco tissue cultures. Physiologia Plantarum, v.15, p.473-497, 1962.

NAP, J.P.; BIJOVOET, J.; STIEKEMA, W. Biosafety of kanamycin-resistant transgenic plants. Transgenic Research, v.1, p.239-249, 1992. 
OCHMAN, H. \& WILSON, A. C. Evolutionary history of enteric bacteria. In: NEIDHARDT, F. C. Escherichia coli and Salmonella typhimurium: cellular and molecular biology. DC: American Society for Microbiology, v.2, p.1649-1654, 1987.

STRAUCH, E.; WOHLLEBEN, W.; PUHLER, A. Cloning of the phosphinothricin Nacetyltransferase gene from Streptomyces viridochromogenes TII 494 and its expression in Streptomyces lividans and Escherichia coli. Gene, v.63, p.65-74, 1988.

THOMPSON, C. J.; RAO MOVVA N.;TIZARD R.; CHAMERI R.; DAVIES J. E.; LAUWEREYS M.; BOTTERMAN J. Characterization of the herbicide-resistant bar gene from Streptomyces hygroscopicus. Embo Journal, v.6, p.2519-2523, 1987.

VAN BOXTEL, J.; ESKES, A.; BERTHOULY, M. Glufosinate as an efficient inhibitor of callus proliferation in coffee tissue. In Vitro Cellular Developmental Biology Plant, v.33, p.6-12, 1997.

VANDERPLANK, J. Passion Flowers. London: Cambridge Press, 1996. 224p.

WILMINK, A.; DONS, J. J. L. Selective agents and markers genes for use in transformation of monocotyledonous plants. Plant Molecular Biology Reporter, v.11, p.165-185, 1993.

WOHLlEBEN, W.; AMOLD, W.; BROER, T.; HILlIMANN, D.; STRAUCH, E.; PIIHLER, A. Nucleotide sequence of the phosphinothricin-N-acetyltransferase gene from Streptomyces viridochromogenes Tii 494 and its expression in Nicotiana tabacum. Gene, v.70, p.25-37, 1988. 